\title{
Trisomy $\mathrm{X}$ in a female member of a family with $\mathrm{X}$ linked severe combined immunodeficiency: implications for carrier diagnosis
}

Tracy Lester, Mahesh de Alwis, Paula A Clark, Alison M Jones, Fay Katz, Roland J Levinsky, Christine Kinnon

\begin{abstract}
We describe a family affected by $X$ linked severe combined immunodeficiency (SCIDX1) in which genetic prediction of carrier status was made using $X$ chromosome inactivation studies together with limited genetic linkage analysis. Linkage studies in this family showed a confusing pattern of inheritance for the $X$ chromosome. A female with a random pattern of $X$ chromosome inactivation in her $T$ cells appeared to have inherited an $X$ chromosome with four recombinations within $10 \mathrm{cM}$. The odds of this happening in a single meiotic event make this an unlikely explanation. Data obtained from studying the $X$ chromosomes of her two unaffected sons showed that this could be explained simply on the basis of her having inherited three alleles each of the relevant polymorphic DNA loci. We used fluorescent in situ hybridisation (FISH) to confirm that this person had inherited three complete $X$ chromosomes. Thus, although the results from $X$ chromosome inactivation analysis indicated that this subject was not a carrier of the affected chromosome, FISH and genetic linkage analysis showed clearly that the affected chromosome had been inherited. The implications of this finding for diagnosis of carrier status in this family and for other families with $X$ linked inherited immunodeficiencies is discussed.
\end{abstract}

( $(\mathcal{M}$ Med Genet 1994;31:717-720)

$\mathrm{X}$ linked severe combined immunodeficiency (SCIDX1) is a disorder which manifests itself clinically as a loss of cellular, and often also humoral, immunity, owing to a lack of peripheral $T$ cells. SCIDX1 patients therefore suffer from frequent infections, which are fatal by 1 to 2 years of age unless successfully treated by bone marrow transplantation. Non-manifesting women who are at risk of carrying a defective copy of the gene for SCIDX1 can be ascertained by determining a non-random pattern of $\mathrm{X}$ chromosome inactivation in their T cells. ${ }^{12}$ Genetic linkage analysis is used to support the diagnosis of carrier status from $\mathrm{X}$ inactivation patterns, or to indicate carrier status where fresh $T$ cell samples cannot be obtained from the females concerned.

Until recently, the gene for SCIDX1 had been mapped crudely to a region in Xq13-q21.1 between the DNA markers DXS132 and DXS447. ${ }^{34}$ Further linkage studies have now refined this location to between DXS135 and DXS227 in Xq13.156 The gene encoding the gamma chain of the interleukin-2 receptor (IL2RG) has also been mapped to this region, ${ }^{7}$ and was found to be mutated in 12 separate SCIDX1 families ${ }^{7-9}$ indicating that mutations in this gene are responsible for SCIDX1.

We have been involved in studies to map new polymorphic markers in this region in several SCIDX1 pedigrees to enable more accurate genetic prediction of carrier status and prenatal diagnosis. Analysis of one family showed a confusing inheritance of alleles which could be interpreted as either the occurrence of a relatively large number of recombinations in two separate meiotic events, or of three copies of the alleles being inherited by one person. We have used fluorescent in situ hybridisation analysis (FISH) to determine which pattern of inheritance is correct.

\section{Materials and methods}

PROBES

Restriction fragment length polymorphisms at various loci (DXS159, DXS106, DXS132, DXS441, DXS347, PGK1, and DXS447 ${ }^{10}$ ) were detected by Southern blot analysis of genomic DNA, using the specific probes and conditions described previously. ${ }^{11}$ In addition, dinucleotide repeat polymorphisms at DXS44 $1^{12}$ and PY2-31, ${ }^{13}$ close to PGK1, were amplified as described, but with slight variations: $\left({ }^{32} \mathrm{P}\right)-\mathrm{dCTP}$ was included in the reaction mixture rather than an end labelled primer, and 30 amplification cycles of $94^{\circ} \mathrm{C}$ for 30 seconds, $50^{\circ} \mathrm{C}$ (PY2-31) or $60^{\circ} \mathrm{C}$ (DXS441) for 60 seconds, $72^{\circ} \mathrm{C}$ for 30 seconds, were used. Following amplification, alleles were separated on $6 \%$ denaturing polyacrylamide gels and detected by autoradiography. The SSCP in intron 1 of the IL2RG gene ${ }^{7}$ was amplified as described above but with a $55^{\circ} \mathrm{C}$ annealing temperature. Following amplification, the intron 1 product was digested with 10 units of $B g l \mathrm{II}$ for one hour at $37^{\circ} \mathrm{C} ; 10 \mu \mathrm{l}$ of the digested PCR product was analysed on a $1.5 \%$ agarose gel, and samples diluted between two and nine times in $10 \mathrm{mmol} / 1$ EDTA, $0.1 \%$ SDS dependent on the efficiency of amplification. An equal volume of a solution containing $95 \%$ deionised formamide, $20 \mathrm{mmol} / 1$ EDTA, $0.05 \%$ bromophenol blue, and $0.05 \%$ xylene cyanol was then added and samples denatured at $95^{\circ} \mathrm{C}$ for three minutes and plunged into 
ice before $4 \mu \mathrm{l}$ was loaded onto a $6 \%$ nondenaturing polyacrylamide gel containing $10 \%$ glycerol, alongside an undenatured control sample. Gels were run at $4^{\circ} \mathrm{C}$ at $60 \mathrm{~W}$ for at least 5.5 hours, and alleles visualised by autoradiography. The dinucleotide repeat at the DXS995 locus was used as described. ${ }^{14}$ The genetic and physical order of these markers, which extend over approximately $16 \mathrm{cM},{ }^{15}$ is as follows: DXS159-DXS-

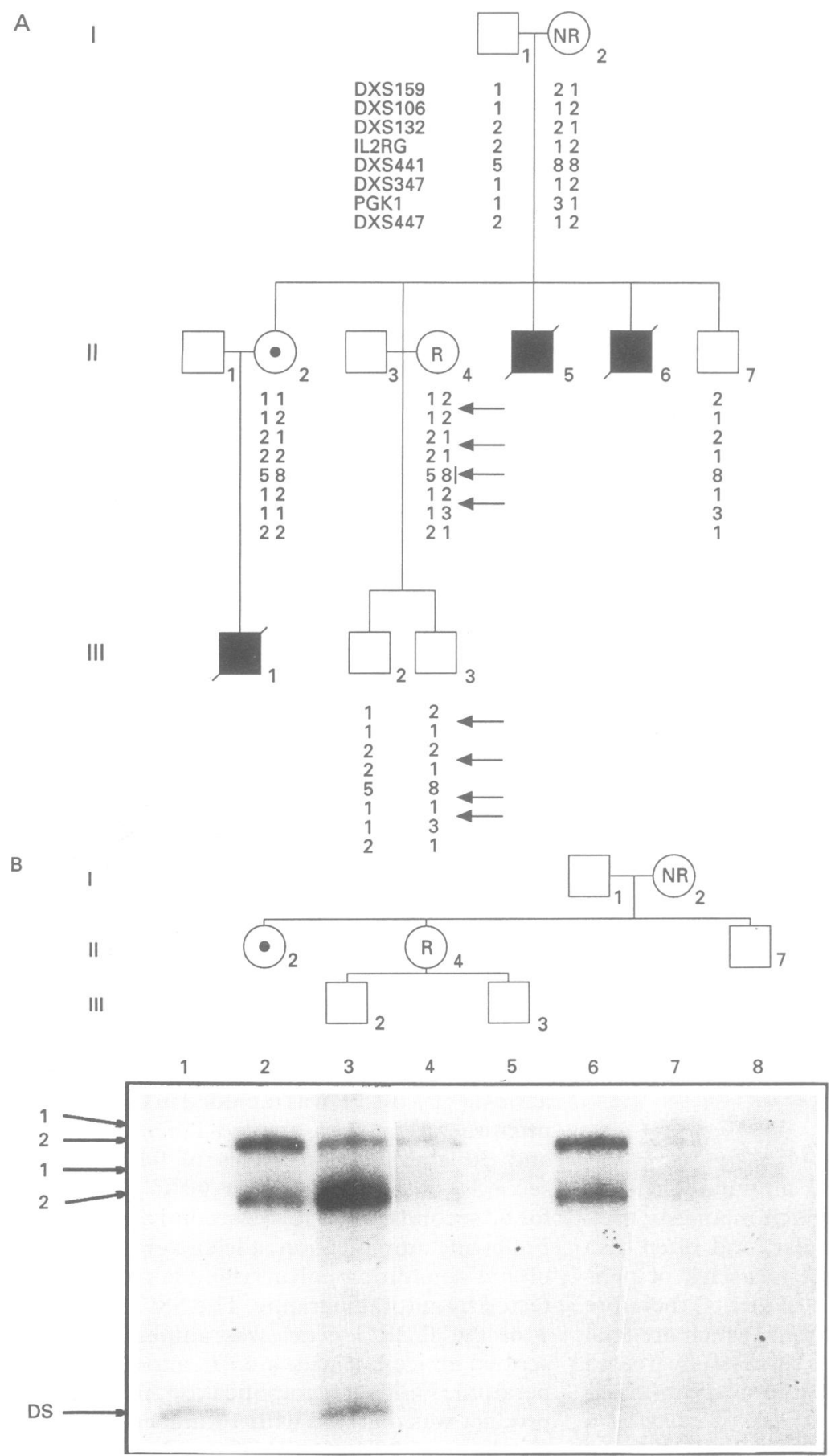

Figure 1 (A) pedigree of the family showing individual haplotypes at eight polymorphic marker loci. Black dot indicates an obligate carrier; $N R=$ unilateral pattern of $X$ inactivation; $R=$ random pattern of $X$ inactivation. Black squares represent affected males. Numbers 1 and 2 differentiate the SSCP alleles, and indicate, respectively, presence or absence of an $R F L P$ site. Alleles of decreasing $C A_{n}$ repeat length are distinguished by numbers from 1-8. Arrows indicate minimum region in which a recombination is presumed to have taken place. (B) Inheritance of alleles at the SSCP within intron 1 of IL2RG, the results of which indicate that II.4 has not inherited the affected allele. Lane 1 is undenatured normal DNA. Lanes 2-7 are denatured samples, loaded according to the partial pedigree shown above the gel. Single strands corresponding to alleles 1 and 2 are labelled to the left of the figure. DS is double stranded DNA.
106-DXS132-IL2RG-(DXS347, PGK1))-DXS447-DXS995. ${ }^{561416}$

(DXS441-

The correct assignment of paternity was checked by hybridisation of HinfI digested DNA using the hypervariable markers D7S21, D7S22, ${ }^{17}$ and D15S86. ${ }^{18}$

FLUORESCENT IN SITU HYBRIDISATION

The methods ised for both interphase and metaphase FISH were essentially as described by Katz et $a l,{ }^{19}$ with slight modifications as summarised below.

\section{Metaphase FISH}

Mitoses were obtained for analysis from cryopreserved peripheral blood mononuclear cells, cultured for three days before analysis in $1 \mathrm{ml}$ of RPMI 1640 (Life Technologies Ltd, UK) supplemented with $1 \mathrm{mmol} / \mathrm{l} \mathrm{L}$-glutamine (Life Technologies Ltd, UK), $20 \%$ FCS (Globepharm Ltd, UK), $50 \mu \mathrm{g} / \mathrm{ml}$ gentamycin (Life Technologies Ltd, UK) 25 units/ml human recombinant interleukin-2, and $60 \mathrm{ng} / \mathrm{ml}$ phytohaemaglutinin (Murex Diagnostics, UK) at $37^{\circ} \mathrm{C}$ in $5 \% \mathrm{CO}_{2}$. The cells were harvested and $\mathrm{G}$ banded using standard procedures. Duplicate slides were then denatured and dehydrated before being incubated overnight at $37^{\circ} \mathrm{C}$ with $15 \mu \mathrm{l}$ of a biotinylated $\mathrm{X}$ specific whole chromosome paint (Cambio, UK).

\section{Interphase FISH}

Cryopreserved peripheral blood mononuclear cells were thawed rapidly, washed twice with PBS, resuspended at $10^{6}$ cells $/ \mathrm{ml}$ in methanol: acetic acid 3:1, and one or two drops of fixed cells placed in the centre of clean, dry, glass slides. Once dry, slides were dehydrated, then denatured in $76 \%$ formamide/ $2 \times$ SSC for two minutes at $70^{\circ} \mathrm{C}$ before dehydrating again; $10 \mathrm{ng}$ each of biotinylated chromosome $\mathrm{X}$ specific and digoxygenin labelled chromosome 7 specific $\alpha$ satellite probes (Oncor, Gaithersburg, USA) were combined and diluted into the hybridisation mixture, denatured, preannealed, and then hybridised to the slides overnight.

\section{Signal detection}

Following hybridisation, slides were washed and the signal detected using $5 \mu \mathrm{g} / \mathrm{ml}$ avidinFITC (Vector Labs, UK) for detection of the biotinylated $\mathrm{X}$ chromosome specific probes, and $5 \mu \mathrm{g} / \mathrm{ml}$ anti-digoxygenin-RITC (Boehringer, UK) for detection of the digoxygenin labelled chromosome 7 specific probe. Incubations were performed in the dark. Following signal amplification with biotinylated anti-avidin (Vector Labs, UK), slides were mounted in antifade solution (Citifluor Ltd) containing $2 \mu \mathrm{g} / \mathrm{ml}$ of the counterstain DAPI (Sigma, UK) and examined using a Zeiss Axioskop microscope equipped with a CCD camera (Photometrics, UK) connected to a Macintosh Quadra computer. Image analysis was performed using an IP Lab (UK) spectrum package. 


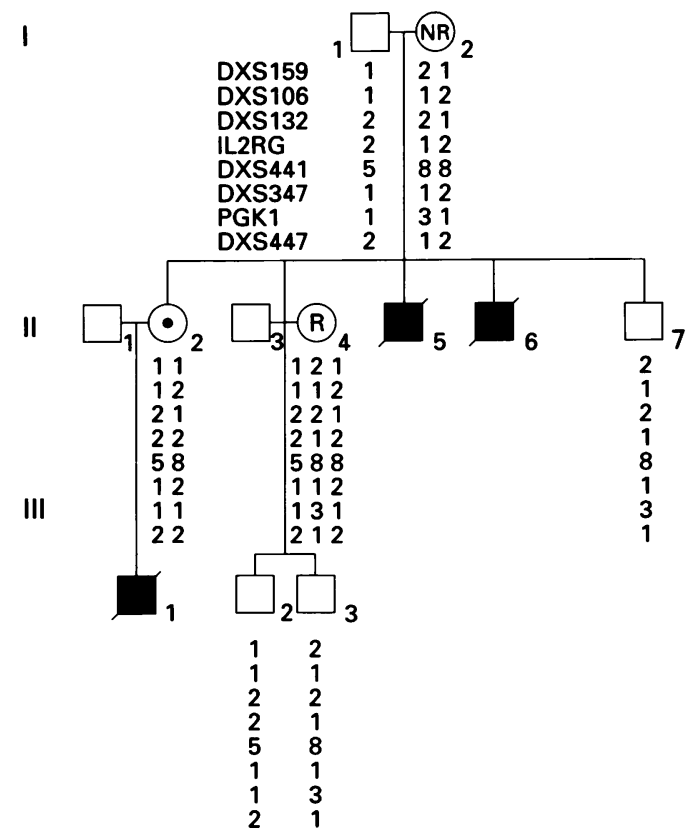

Figure 2 Pedigree of the family showing the inheritance of trisomy X. Symbols and numbers are described in the legend to fig $1 A$.

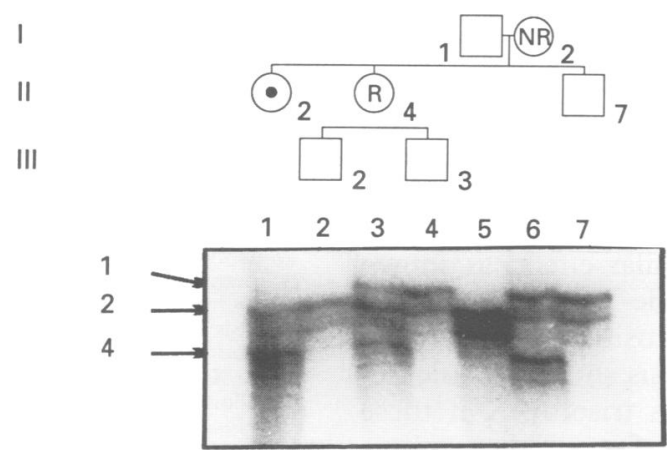

Figure 3 Inheritance of alleles at DXS995. A partial pedigree is shown above the gel, corresponding to the loading of lanes 1-7. The alleles are labelled to the left of the figure. Although a number of "shadow" bands are present, it is apparent that II.4 has inherited all three alleles (alleles 1 and 2 can be distinguished on the basis of inheritance by her two sons).

\section{Results}

The results of linkage studies in this family are shown in fig 1A. A recombination between the markers DXS159 and DXS106 in subject II $\cdot 4$, a female with no affected sons, was described previously. ${ }^{20} \mathrm{X}$ chromosome inactivation studies in the $\mathrm{T}$ cells of this person suggested that she was unlikely to be a carrier of SCIDX1 since the inactivation pattern appeared to be random. ${ }^{20}$ Further linkage studies showed a second recombination in the same chromosome, between the markers DXS347 and PGK1, suggesting that subject II 4 had inherited the carrier chromosome in the region of the IL2RG gene. However, analysis with the SSCP in intron 1 of IL2RG showed that the normal copy of this gene had been inherited (fig 1B), suggesting a further two recombinations in this chromosome. Results using the hypervariable markers D7S21, D7S22, and D15S86 indicated that paternity was likely to

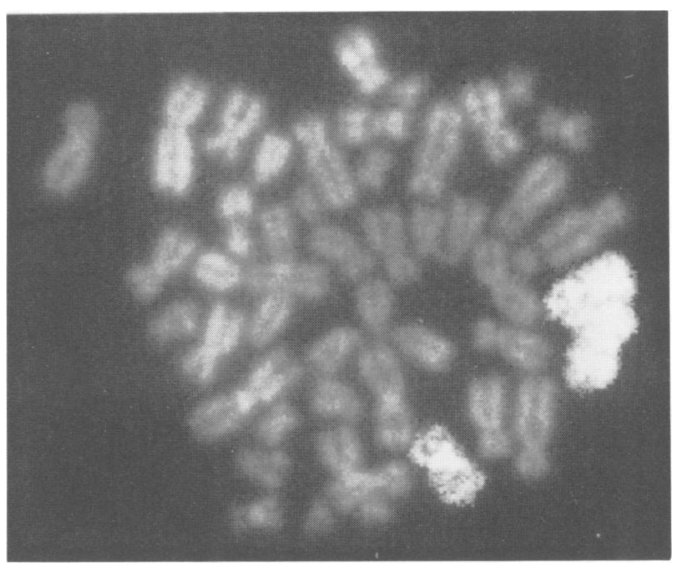

Figure 4 FISH analysis of a metaphase spread from a $T$ cell of subject II.4, showing the presence of three complete $X$ chromosomes ("painted" white).

be as assigned, and that the DNA from subject II. 4 had not been contaminated by DNA from other members of the family (results not shown).

We then studied the two unaffected sons of subject II $\cdot 4$ and showed that one, subject III $\cdot 2$, had inherited the grandpaternal chromosome. However, the second son (subject III·3) appeared to have inherited a chromosome with four recombinations (fig 1A). According to Drayna and White, ${ }^{21}$ between one and four recombinations would be expected on the $\mathrm{X}$ chromosome in each meiosis. However, in this family, four recombinations appear to have occurred within only a very small region of the $\mathrm{X}$ chromosome in two separate meioses. Since the probability of this occurring is therefore very low, we looked for a simpler explanation for the inheritance of alleles in this family. Since subject III.3 had inherited the same chromosome as his uncle (II-7) it seemed likely that his mother (II.4) had also inherited this chromosome. The confusing pattern of alleles in subject II 4 could therefore be because of the presence of a third chromosome as a result of a non-disjunction event in the gamete from I. 2 (fig 2).

In order to test this theory, we first used the hypervariable microsatellites DXS986, DXS995, and DXS1002 to try to identify all three chromosomes inherited by subject II 4 . Only DXS995 was found to have different alleles for the three chromosomes, and subject II. 4 was found to have inherited all three of these alleles (fig 3 ). We then used FISH analysis on interphase lymphocytes from subject II 4 using $\alpha$ satellite chromosome specific probes for chromosomes X and 7 (as a control). This showed that subject II 4 had three copies of the X chromosome specific probe in her cells, as opposed to only two copies of the chromosome 7 specific probe as expected (data not shown). Finally we repeated FISH on dividing $\mathrm{T}$ cells using an $\mathrm{X}$ chromosome specific paint, and showed the presence of 47 chromosomes, with three complete $\mathrm{X}$ chromosomes, in 10 out of 10 separate metaphases from the cells of subject II 4 (fig 4 ). 


\section{Discussion}

A non-manifesting female in a SCIDX1 pedigree was diagnosed as not carrying the mutated allele on the basis of a random pattern of $\mathrm{X}$ inactivation in her $T$ cells. We have now shown that this woman has inherited three complete $\mathrm{X}$ chromosomes, one of which is the chromosome carrying the SCIDX1 mutation. Since this X chromosome will appear inactivated in all her $T$ cells, the random $X$ inactivation pattern has arisen as a result of her random inactivation of the other two non-mutant $\mathrm{X}$ chromosomes. This woman is therefore a carrier of SCIDX1 despite previous evidence to the contrary.

Trisomy $\mathrm{X}$ is reported to occur at a frequency of about 1 in 1000 women and, although intelligence tends to be below average, and approximately $25 \%$ of such women are infertile, there are no obvious abnormalities. ${ }^{22} 23$ There is therefore a low risk for women in pedigrees affected by other $\mathrm{X}$ linked disorders having their carrier status misdiagnosed owing to this phenomenon. For example, carriers of other $\mathrm{X}$ linked immunodeficiencies, such as agammaglobulinaemia (XLA) and Wiskott-Aldrich syndrome (WAS), have also been determined by detection of non-random $\mathrm{X}$ chromosome inactivation patterns in purified $B$ cells or whole blood, respectively. ${ }^{24-27}$

Failure to identify events such as trisomy $\mathrm{X}$ in genetic linkage studies of $\mathrm{X}$ linked disorders could lead to the incorrect interpretation of marker genotypes and hence incorrect localization of the gene. Partial chromosomal duplications can have a similar effect, as shown by studies of Charcot-Marie-Tooth disease type $1 \mathrm{~A} .{ }^{28}$ The use of more sensitive hypervariable markers for linkage analysis should enable detection of such events as trisomy $\mathrm{X}$ if these markers are informative for all three chromosomes. In addition, the cloning of the genes involved in such disorders will enable unambiguous assignment of carrier status even in such cases of unusual inheritance. SCIDX1, for example, is caused by mutations in IL2RG, ${ }^{78}$ and mutations in a tyrosine kinase gene (Btk) have recently been shown to cause XLA, ${ }^{29-31}$ enabling unambiguous assignment of carrier status and prenatal diagnosis in families affected by these disorders. ${ }^{32}$

We would like to thank members of the family and their clinicians for their cooperation, Brian Reeves, Helena Kempski, and Kalyani Jani for their help with the FISH analysis, and Mary Collins for her kind gift of recombinant human interleukin-2 We are also grateful to the Gillian Fabb Fund for providing the CCD camera. TL and MDA were funded by a project gran from the Medical Research Council and PC by a studentship from the Child Health Research Appeal Trust of the Institute of Child Health.

1 Puck JM, Nussbaum RL, Conley ME. Carrier detection in $\mathrm{X}$-linked severe combined immunodeficiency based on patterns of $\mathrm{X}$ chromosome inactivation. 7 Clin Invest 1987 79:1395-400.

2 Goodship J, Malcolm S, Lau YL, Pembrey ME, Levinsky RJ. Use of $\mathrm{X}$ chromosome inactivation analysis to establish carrier status for X-linked severe combined imcarrier status for X-linked severe
munodeficiency. Lancet 1988;i:729-32.

3 Puck JM, Stewart CC, Conley ME, Nussbaum RL. Narrowing the boundaries for $\mathrm{X}$-linked severe combined immunodeficiency (SCIDX1) in Xq13.1-q21.1 by linkage munodeficiency (SCIDX1) in Xq13.1-q21.1 by linkage
4 Puck JM. Bailey LC, Conley ME. Update on linkage of Xlinked severe combined immunodeficiency (SCIDX1) to loci in Xq13. Cytogenet Cell Genet 1992;58:2082.

5 Markiewicz S, DiSanto JP, Chelly J, et al. Fine mapping of the human SCIDX1 locus at Xq12-13.1. Hum Mol Genet 1993;2:651-4

6 Puck JM, Conley ME, Bailey LC. Refinement of linkage of human severe combined immunodeficiency (SCIDX1) to polymorphic markers in Xq13. Am $\mathcal{F}$ Hum Genet 1993; 53:176-84

7 Noguchi M, Yi H, Rosenblatt HM, et al. Interleukin-2 receptor $\gamma$ chain mutation results in X-linked severe comreceptor $\gamma$ chain mutation results in X-linked severe com-

8 Puck JM, Deschenes SM, Porter JC, et al. The interleukin2 receptor $\gamma$ chain maps to Xq13.1 and is mutated in 2 receptor $\gamma$ chain maps to Xq13.1 and is mutated in
$\mathrm{X}$-linked severe combined immunodeficiency, SCIDX1. X-linked severe combined immun

9 DiSanto JP, Dautry-Varsat A, Certain S, Fischer A, de Saint Basile G. Interleukin-2 (IL-2) receptor $\gamma$ chain mutations in X-linked severe combined immunodeficiency disease result in the loss of high-affinity IL-2 receptor binding. Eur f Immunol 1994;24:475-9.

10 Davies KE, Mandel JL, Monaco AP, Nussbaum RL, Willard HF. Report of the commitee on the genetic constitution of the X chromosome. Cytogenet Cell Genet 1990;55:254-313.

11 Jones AM, Malcolm S, Levinsky RJ, Kinnon CK. Physica mapping in the region of human Xq12-21.1 using pulsed field gel electrophoresis. Hum Genet 1993;91:485-8.

12 Ram KT, Barker DF, Puck JM. Dinucleotide repeat polymorphism at the DXS441 locus. Nucleic Acids Res 1992; 20:1428.

13 Graeber MB, Kupke KG, Müller U. Delineation of the dystonia-parkinsonism syndrome locus in Xq13. Proc Natl Acad Sci USA 1992;89:8245-8.

14 Clark PA, Lester T, Villard L, Fontes M, Kinnon C. Deletion mapping of the DXS986, DXS995, and DXS1002 loci defines their order within Xq21. F Med Genet 1994;31: 344-5.

$15 \mathrm{NIH} / \mathrm{CEPH}$ collaborative mapping group. A comprehensive genetic linkage map of the human genome. Science 1992 258:67-162.

16 Lafreniere RG, Brown CJ, Powers VE, et al. Physical mapping of 60 DNA markers in the p21.1-q21.3 region of the human X chromosome. Genomics 1991;11:352-63.

17 Royle NJ, Clarkson RE, Wong Z, Jeffreys AJ. Clustering of hypervariable minisatellites in the proterminal regions of human autosomes. Genomics 1988;3:352-60.

18 Armour JA, Povey S, Jeremiah S, Jeffreys AJ. Systematic cloning of human minisatellites from ordered array charomid libraries. Genomics 1990;8:501-12.

19 Katz F, Reeves BR, Alexander S, Kearney L, Chessells J. Leukaemia arising in donor cells following allogenic bone marrow transplantation for $\beta$ thalassaemia demonstrated by immunological, DNA and molecular cytogenetic anaby immunological, DNA and molecular
lysis. Br f Haematol 1993;85:326-31.

20 Goodship J, Levinsky R, Malcolm S. Linkage of PGK to X-linked severe combined immunodeficiency (IMD4) allows predictive testing in families with no surviving male. Hum Genet 1989;84:11-14

21 Drayna $D$, White $R$. The genetic linkage map of the huma $\mathrm{X}$ chromosome. Science 1985;230:753-8.

22 Gardner RIM, Sutherland GR. Chromosome abnormalities and genetic counselling. Oxford: Oxford University Press, 1989. 23 Vogel F, Motulsky V, eds. Human genetics: problems and approaches. 2nd ed. Berlin: Springer-Verlag, 1986.

24 Conley ME, Puck JM. Carrier detection in typical and atypical X-linked agammaglobulinemia. F Pediatr 1988 112:688-94.

25 Fearon ER, Kohn DB, Winkelstein JA, Vogelstein B, Blaese RM, Carrier detection in the Wiskott-Aldrich syndrome. Blood 1987;72:1735-9.

26 Goodship J, Carter J, Espanol T, Boyd Y, Malcolm S, Levinsky RJ. Carrier detection in Wiskott-Aldrich syndrome: combined use of $M 27 \beta$ for $\mathrm{X}$-inactivation studies and as a linked probe. Blood 1991;77:2677-81.

27 Alterman LA, de Alwis M, Genet S, et al. Carrier determination for X-linked agammaglobulinaemia using X termination for $\mathrm{X}$-linked agammaglobulinaemia using $\mathrm{X}$ inactivation analysis

28 Lupski JR, Garcia CA. Molecular genetics and neuropathology of Charcot-Marie-Tooth disease type 1A. Brain Pathol 1992;2:337-49.

29 Vetrie D, Vorechovsky I, Sideras P, et al. The gene involved in X-linked agammaglobulinaemia is a member of the src family of protein-tyrosine kinases. Nature 1993;361: 226-33.

30 Bradley LAD, Sweatman AK, Lovering RC, et al. Mutation detection in the gene for $\mathrm{X}$-linked agammaglobulinaemia btk, using single strand conformational polymorphism analysis. Hum Mol Genet 1994;3:79-83.

31 de Weers M, Mensink RGJ, Kraakman MEM, Schuurman RKB, Hendriks RW. Mutation analysis of the Bruton's tyrosine kinase gene in X-linked agammaglobulinemia: tyrosine kinase gene in $\mathrm{X}$-linked agammaglobulinemia: identification of a mutation which affects the same codon as is altered in

32 Lovering RC, Sweatman AK, Genet SA, et al. Identification of deletions in the $b t k$ gene allows unambiguous assessment of deletions in the btk gene allows unambiguous assessment maglobulinemia. Hum Genet (in press). 